\title{
Teste de germinação sob condições de restrição hídrica para avaliar o vigor de sementes de girassol
}

\author{
Germination test under water restriction to evaluate sunflower seeds vigor
}

\author{
Camila Santos Barros ${ }^{\mathrm{I}}$ Claudia Antonia Vieira Rossetto ${ }^{\mathrm{I}^{*}}$
}

\begin{abstract}
Diferentes testes de vigor têm sido utilizados para classificar os lotes de sementes. Assim, os objetivos do presente trabalho foram avaliar o vigor de diferentes lotes de sementes (aquênio = pericarpo mais semente) de girassol, usando o teste de germinação sob restrição hídrica, e correlacionar os resultados dessa metodologia com os de outros testes de vigor. Cinco lotes de girassol da cultivar 'Catissol' foram primeiramente submetidos aos testes de germinação e de vigor. Posteriormente, os lotes foram submetidos ao teste de germinação sob restrição hídrica. As sementes foram distribuídas em substrato de papel umedecido com solução de PEG 6000 a -0,3 e -0,6MPa. O teste de germinação sob -0,6MPa, aos 10 dias da instalação, foi eficiente na detecção de diferenças na qualidade fisiológica entre lotes de sementes de girassol. $O$ resultado do teste de germinação sob -0,6MPa, aos 10 dias, correlaciona-se significativamente com os resultados dos testes de IVE, emergência de plântulas, primeira contagem e envelhecimento acelerado.
\end{abstract}

Palavras-chave: germinação, Helianthus annuus L., potencial hídrico, qualidade fisiológica.

\section{ABSTRACT}

Different vigour tests have been used to classify seed lot. The aim was to evaluate the effect of different sunflower seeds (achenes $=$ pericarp + seed) using the germination test under water restriction and to correlate the results of this methodology with other vigour tests. Five sunflower lots were studied and were evaluated firstly by the germination test and vigour tests. After, the seed lots was submitted to germination test under water restriction. Seeds were distributed on paper substrate moistened with a PEG 6000 solution by the -0.3 and
-0.6MPa. The germination under -0.6MPa, after 10 days, was efficient in the detection of physiological quality differences between sunflower seed lot. The result of the germination test under $-0.6 \mathrm{MPa}$ by 10 days correlates significantly with the results of the IVE test, seedling emergence test, the first counting test and aging test.

Key words: germination, Helianthus annuus L, water potential, physiological quality.

A área cultivada com girassol vem aumentando em diversas regiões do Brasil. Nas regiões Nordeste e Sul, o aumento foi, respectivamente, de 1,0 e de 5,2 mil hectares, da safra de 07/08 para a de 08/09 (CONAB, 2009). O cultivo dessa espécie está sujeito às variações edafoclimáticas, em especial a disponibilidade hídrica do solo, na ocasião da semeadura (BACKES et al., 2008). Sementes de diversas espécies, quando submetidas à restrição hídrica no solo, reduzem a germinação e o desenvolvimento em razão da interferência no processo de embebição e de alongamento celular (MARCOS FILHO, 2005), pois há redução no acúmulo de prolina, substância responsável pelo ajustamento osmótico das células (SCHUAB et al., 2007). Além disso, nessas condições de estiagem, o desempenho das plantas depende da qualidade das sementes. ALBUQUERQUE \& CARVALHO (2003) verificaram que a influência do vigor das sementes de girassol na redução da emergência está associada à

IDepartamento de Fitotecnia, Instituto de Agronomia, Universidade Federal Rural do Rio de Janeiro (UFRRJ), CP 74511, 23890000, Seropédica, RJ, Brasil. E-mail: cavrosse@ufrrj.br. *Autor para correspondência. 
condição de estresse a qual estas foram submetidas. Sementes com maior vigor, previamente avaliadas pelo teste de envelhecimento acelerado, proporcionaram menor redução da emergência de plântulas sob restrição hídrica de -1,1MPa que as de menor vigor.

Em laboratório, com o objetivo de avaliar a qualidade das sementes, também tem sido empregado o teste de germinação sob restrição hídrica, utilizando polietilenoglicol e correlacionando os resultados obtidos com os dos demais testes de vigor, como os que avaliam a classificação do vigor de plântulas e as alterações bioquímicas. Em soja, SCHUAB et al. (2007) verificaram que o teste de germinação sob - $0,2 \mathrm{MPa}$ apontou diferenças no vigor das sementes e que houve correlação com os resultados dos testes de envelhecimento acelerado, primeira contagem e índice de velocidade de emergência. Portanto, com esses testes, as empresas produtoras de sementes podem procurar selecionar lotes com desempenho superior, capazes de germinar em condições de estresse ambiental, tal como estiagem na época da semeadura. Assim, os objetivos deste trabalho foram avaliar o vigor de lotes de sementes de girassol, usando o teste de germinação sob restrição hídrica, e correlacionar os resultados dessa metodologia com os de outros testes de vigor utilizados para sementes de girassol.

O experimento foi realizado no laboratório de análise de sementes da Universidade Federal Rural do Rio de Janeiro, em 2007. Foram utilizados cinco lotes de sementes de girassol da cultivar 'Catissol 01', da safra 2006/2007, peneira 12, provenientes da Coordenadoria de Assistência Técnica Integral. Os lotes foram submetidos aos testes de germinação e de vigor, com quatro subamostras de 50 sementes.

O teste de germinação foi conduzido em rolo de papel, a $25^{\circ} \mathrm{C}$. As avaliações foram realizadas aos quatro e 10 dias após a instalação (BRASIL, 1992). Em conjunto, foi realizado o teste de primeira contagem (NAKAGAWA, 1999). Para teste de envelhecimento acelerado, 250 sementes $(10,5 \mathrm{~g})$ foram distribuídas sobre tela, no interior de câmara contendo no fundo $40 \mathrm{ml}$ de solução de $\mathrm{NaCl}$ e mantidas a $42^{\circ} \mathrm{C}$, durante 96 horas (BRAZ et al., 2008). O teste de condutividade elétrica foi realizado com quatro subamostras de 25 sementes (após a remoção do pericarpo). Estas foram imersas em água destilada por 24 horas, a $25^{\circ} \mathrm{C}$ (BRAZ et al., 2008). $\mathrm{O}$ teste de emergência de plântulas foi realizado em substrato areia. As avaliações foram realizadas diariamente durante 21 dias após a semeadura, visando à avaliação da porcentagem de emergência de plântulas e ao cálculo do índice de velocidade de emergência (IVE) (NAKAGAWA,1999). Para o teste de germinação sob restrição hídrica, as sementes foram distribuídas em substrato de papel germitest umedecido com soluções de polietilenoglicol 6000 sob -0,3 e -0,6MPa (MICHAEL \& KAUFMANN, 1973) e mantidas a $25^{\circ} \mathrm{C}$ na ausência de luz. As avaliações foram efetuadas conforme o teste de germinação. Em conjunto, no teste germinação, foi considerada a porcentagem de plântulas normais, obtidas na primeira avaliação. $\mathrm{O}$ delineamento experimental utilizado foi o inteiramente casualizado, com quatro repetições. Os dados foram submetidos aos testes de normalidade e homogeneidade e, em seguida, à análise de variância. As médias foram comparadas pelo teste Tukey, a 5\% de probabilidade (GOMES, 1991). Também foi realizada a análise de correlação linear entre os resultados dos testes de germinação sob restrição hídrica e dos demais.

Pelos resultados do teste de germinação, as sementes de girassol dos lotes 1 e 5 apresentaram os menores valores de porcentagem, e as sementes do lote 3, o maior valor, embora estes não tenham diferido do apresentado pelas sementes dos lotes 2 e 4 (Tabela 1). Assim, de acordo com DELOUCHE \& BASKIN (1973), há limitação do teste de germinação para a detecção de diferenças não acentuadas na qualidade fisiológica entre lotes de sementes. Pelo teste de primeira contagem, as sementes de girassol dos lotes 2, 3 e 4 apresentaram-se superiores a sementes do lote 5 , embora este não tenha diferido dos do lote 1 . No entanto, pelo teste de envelhecimento acelerado, as sementes de girassol dos lotes 2 e 3 apresentaram os maiores valores de porcentagem de plântulas normais, quando comparadas com as dos lotes 1 e 4, não diferindo dos valores das sementes do lote 5 . O teste de condutividade elétrica revelou que somente as sementes do lote 1 apresentaram maior lixiviação de solutos, indicando esse lote como de baixo vigor. Para BRAZ et al. (2008), os testes de condutividade elétrica e de envelhecimento (pelo sistema salino) são eficientes para indicar diferenças entre lotes de sementes de girassol. Pelo teste de emergência de plântulas, as sementes dos lotes 1, 2 e 3 apresentaram os maiores valores de porcentagem. No entanto, segundo SCHUAB et al. (2007), esse teste apontou resultados inconsistentes, pois não foi eficiente em indicar diferenças de potencial fisiológico entre os lotes de sementes de soja, quando comparado aos demais testes de vigor. Esse resultado também foi constatado para as sementes do lote 1 . Na avaliação do IVE, as sementes de girassol dos lotes 2 e 3 demonstraram nível superior às sementes do lote 5 , que, por sua vez, não diferiram das dos lotes 1 e 4 .

Sob -0,3MPa, aos quatro dias da instalação, as sementes dos lotes 1 e 2 demonstraram desempenho superior às sementes dos demais. Também aos 10 dias 
Tabela 1 - Dados médios de germinação (G), de plântulas normais na primeira contagem (PC), de envelhecimento acelerado (EA), de condutividade elétrica (CE), de emergência das plântulas (EP), de índice de velocidade de emergência de plântulas (IVE) e de plântulas normais sob potencial hídrico de -0,3 e -0,6MPa aos quatro dias (4D) de 10 dias (10D) após a instalação.

\begin{tabular}{|c|c|c|c|c|c|c|c|c|c|c|}
\hline \multirow{3}{*}{ Lotes } & \multirow{3}{*}{$\begin{array}{c}\mathrm{G} \\
(\%)\end{array}$} & \multirow{3}{*}{$\begin{array}{l}\text { PC } \\
(\%)\end{array}$} & \multirow{3}{*}{$\begin{array}{l}\text { EA } \\
(\%)\end{array}$} & \multirow{3}{*}{$\begin{array}{c}\mathrm{CE} \\
(\mu \mathrm{S} / \mathrm{cm} / \mathrm{g})\end{array}$} & \multirow{3}{*}{$\begin{array}{l}\text { EP } \\
(\%)\end{array}$} & \multirow{3}{*}{ IVE } & \multicolumn{4}{|c|}{------------Plântulas normais (\%)---------' } \\
\hline & & & & & & & \multicolumn{2}{|c|}{$-0,3 \mathrm{MPa}$} & \multicolumn{2}{|c|}{$-0,6 \mathrm{MPa}$} \\
\hline & & & & & & & $4 \mathrm{D}$ & $10 \mathrm{D}$ & $4 \mathrm{D}$ & $10 \mathrm{D}$ \\
\hline 1 & $87 b^{*}$ & $73 b c$ & $63 c$ & 53,18a & $95 a$ & $14,75 b c$ & $62 a$ & 87ab & $31 a$ & $65 b$ \\
\hline 2 & 93ab & $84 a$ & $86 a$ & $42,62 b$ & $97 a$ & $16,54 a$ & $64 a$ & $89 a$ & $32 a$ & $75 a$ \\
\hline 3 & $94 a$ & $83 a$ & 81ab & $44,08 b$ & $96 a$ & $15,02 \mathrm{ab}$ & $47 b$ & 88ab & $21 b$ & $74 a$ \\
\hline 4 & $88 a b$ & 78ab & $64 c$ & $44,86 b$ & $83 b$ & $14,34 b c$ & $35 c$ & $83 \mathrm{~b}$ & $29 a$ & $56 c$ \\
\hline 5 & $87 b$ & $72 c$ & 69bc & $44,76 b$ & $82 b$ & 13,31c & $35 c$ & $69 c$ & $17 \mathrm{~b}$ & $44 d$ \\
\hline CV (\%) & 3,19 & 3,27 & 7,56 & 6,57 & 2,93 & 4,78 & 5,48 & 2,49 & 12,47 & 3,57 \\
\hline
\end{tabular}

* Médias seguidas da mesma letra não diferem entre si pelo teste de Tukey $(\mathrm{P}=0,05)$.

foi verificado que as sementes dos lotes 1,2 e 3 apresentaram desempenho superior as do lote 5 . O resultado apresentado pelo lote 1 pode estar relacionado ao fato de que sob -0,3MPa há redução na velocidade de entrada de água nas células, vindo a proporcionar o envigoramento de sementes menos vigorosas, pela redução dos danos causados pela rápida embebição, como também constatado para sementes de soja por SILVA et al. (2006). Já sob -0,6MPa, aos quatro dias, foi constatado que houve agrupamento dos lotes 1, 2 e 4 como os de desempenho superior e dos lotes 3 e 5 como os de menor desempenho. Aos 10 dias, as sementes de girassol dos lotes 2 e 3 foram os que apresentaram melhor desempenho e as do lote 5, o menor. Assim, sob 0,6MPa, a germinação reduziu de forma mais acentuada, principalmente em lotes com menor nível de vigor. Esse potencial hídrico, de acordo com KAYA et al. (2006), já é considerado crítico para a germinação por causar restrição hídrica. Além disso, de acordo com SILVA et al. (2006), sob maior restrição hídrica, ocorre o prolongamento da fase estacionária do processo de embebição, devido à redução da atividade enzimática, levando ao menor desenvolvimento meristemático e, consequentemente, ao atraso na germinação. Além disso, o teste de germinação sob -0,6MPa apontou a mesma classificação dos lotes pelos testes de primeira contagem, envelhecimento acelerado e IVE, especialmente, entre os de maior e menor nível de vigor. Em soja, SILVA et al. (2006) indicaram o teste de germinação sob -0,6MPa como procedimento promissor para a avaliação do potencial fisiológico das sementes dessa espécie.

Pela análise de correlação, os resultados dos testes de germinação sob -0,3 e -0,6MPa, aos quatro dias, correlacionaram-se significativamente com os dos testes de IVE e de emergência de plântulas (Tabela 2). Já, aos 10 dias, os resultados dos testes de germinação sob -0,3MPa, além de se correlacionarem com os resultados desses dois testes, ao quarto dia da instalação, também se correlacionaram- com os testes de germinação e de primeira contagem. Os resultados do teste germinação sob - $0,6 \mathrm{MPa}$ apresentaram correlação significativa com os dos testes de primeira contagem, de envelhecimento acelerado, IVE e de emergência de plântulas. Em soja, SCHUAB et al. (2007)

Tabela 2 - Coeficiente de correlação de Pearson entre os resultados do teste de germinação sob estresse hídrico de -0,3 e -0,6MPa aos quatro e 10 dias após a instalação e os dos testes de germinação (G), de primeira contagem (PC), de envelhecimento acelerado (EA), de condutividade elétrica (CE), de emergência de plântulas (EP) e de índice de velocidade de germinação (IVE), para avaliação da qualidade fisiológica de lotes de sementes de girassol.

\begin{tabular}{|c|c|c|c|c|c|c|}
\hline Parâmetros & G & $\mathrm{PC}$ & EA & $\mathrm{CE}$ & EP & IVE \\
\hline$-0,3$ aos 4 dias & $0,2686^{\mathrm{ns}}$ & $0,2498^{\text {ns }}$ & $0,3225^{\mathrm{ns}}$ & $0,2493^{\text {ns }}$ & $0,8323 * *$ & $0,7280 * *$ \\
\hline$-0,3$ aos 10 dias & $0,4029 *$ & $0,5857 * *$ & $0,3158^{\text {ns }}$ & $0,0694^{\mathrm{ns}}$ & $0,7758 * *$ & $0,7680 * *$ \\
\hline$-0,6$ aos 4 dias & $-0,0226^{\mathrm{ns}}$ & $0,1965^{\text {ns }}$ & $0,0827^{\mathrm{ns}}$ & $0,2171^{\mathrm{ns}}$ & $0,4041^{*}$ & $0,5555^{* *}$ \\
\hline$-0,6$ aos 10 dias & $0,5926 * *$ & $0,7114^{* *}$ & $0,5736^{* *}$ & $-0,0481^{\mathrm{ns}}$ & $0,8538 * *$ & $0,8064^{* *}$ \\
\hline
\end{tabular}

** significativo a $(\mathrm{P}=0,01)$, * significativo a $(\mathrm{P}=0,05)$ e ${ }^{\mathrm{ns}}$ não significativo. 
verificaram correlação significativa entre o teste de germinação sob -0,2MPa e os testes de primeira contagem, velocidade de emergência e envelhecimento acelerado. Pelos resultados, pode-se concluir que o teste de germinação sob -0,6MPa, aos 10 dias, apontou diferenças entre os lotes de sementes de girassol. Há correlação entre os resultados do teste de germinação sob -0,6MPa, avaliado após 10 dias, com os testes de IVE, emergência de plântulas, primeira contagem e envelhecimento acelerado.

\section{REFERÊNCIAS}

ALBUQUERQUE, M.C.de F.; CARVALHO, N.M. Effect of the type of environmental stress on the emergence of sunflower (Helianthus annuus L.) soybean (Glycine max (L.) Merril) and maize (Zea mays L.) seeds with different levels of vigor. Seed Science \& Technology, v.31, n.2, p.465-479, 2003.

BACKES, R.L. et al. Desempenho de cultivares de girassol em duas épocas de plantio de safrinha no planalto norte catarinense. Scientia Agricola, v.9, n.1, p.41-48, 2008. Disponível em: http://ojs.c3sl.ufpr.br/ojs2/index.php/agraria/article/view/10131/ 8174. Acesso em: 14 de out. 2008.

BRASIL. Ministério da Agricultura e Reforma Agrária. Regras para Análise de Sementes. Brasília: SNDA/DNDV/CLAV, 1992. 365p.

CONAB. Acompanhamento da safra brasileira: grãos: nono levantamento, junho 2009/ Companhia Nacional de Desenvolvimento. Brasília: Conab, 2009. 39p.

BRAZ, M.R.S. et al. Testes de envelhecimento acelerado e deterioração controlada na avaliação do vigor de aquênios de girassol. Ciência Rural, v.38, n.7, p.1857-1863, 2008. Disponível em:
<http://www.scielo.br/scielo.php?script=sci_arttext\&pid=S01034782008000700009\&lng=pt\&nrm= iso $>$. Acesso em 17 set. 2008. doi: 10.1590/S0103-84782008000700009.

DELOUCHE, J.C.; BASKIN, N.C. Accelerated aging techniques for predicting the relative storability of seed lots. Seed Science \& Technology, v.1, p.427-452, 1973.

GOMES, F.P. Curso de estatística experimental. Piracicaba: Nobel, 1991. 468p

KAYA, M. D. et al. Seed treatments to overcome salt and drought stress during germination in sunflower (Helianthus annuus L.). European Journal Agronomy, v.24, n.4, p.291295, 2006. Disponível em: <http://dx.doi.org/10.1016/ j.eja.2005.08.001>. Acesso em: 23 mai. 2007.

MARCOS FILHO, J. Fisiologia de sementes de plantas cultivadas. Piracicaba: Fealq, 2005. 495p.

MICHAEL, B.; KAUFMANN, M.R. The osmotic potential of polyethylene glycol 6000. Plant Physiology, v.51, n.6, p.914916, 1973.

NAKAGAWA, J. Testes de vigor baseados no desempenho das plântulas. In: KRZYZANOWSKI, F.C et. al. (Eds.). Vigor de sementes: conceitos e testes. Londrina: ABRATES, 1999. Cap.II, p.1-24.

SCHUAB, S.R.P. et al. Germination test under water stress to evaluate soybean seed vigour. Seed Science \& Technology, v.35, n.1, p.187-199, 2007.

SILVA, J.B. et al. Desempenho de sementes de soja submetida a diferentes potenciais osmóticos em polietilenoglicol. Ciência Rural, v.23, n5, p.1634-1637, 2006. Disponível em: <http:// www.scielo.br/scielo.php?script=sci_arttext\&pid=S010384782006000500047\&lng=pt\&nrm =iso\&tlng=pt $>$. Acesso em: 14 de out. 2008. doi: 10.1590/S0103-84782006000500047. 